\title{
The potential role of angiogenesis in the development of shoulder pain, shoulder dysfunction, and lymphedema after breast cancer treatment
}

This article was published in the following Dove Press journal: Cancer Management and Research

\author{
Trevor S Mafu' \\ Alison V September ${ }^{\prime}$ \\ Delva Shamley ${ }^{2}$ \\ 'Division of Exercise Science and \\ Sports Medicine, Department of \\ Human Biology, Faculty of Health \\ Sciences, University of Cape Town, \\ ${ }^{2}$ Clinical Research Centre, Faculty of \\ Health Sciences, University of Cape \\ Town, Cape Town, South Africa
}

\begin{abstract}
Shoulder morbidity is a well-documented sequela of breast cancer treatment, which includes various manifestations such as pain, reduced range of motion, and lymphedema, among others. The multifactorial nature of such morbidities has long been appreciated, and research on reliable risk predictors of development thereof still continues. Previous studies have demonstrated the potential of different types of physical therapy to treat such shoulder problems, and the integration of such interventions into routine care for breast cancer survivors is a requirement in most high-income countries. Although patients at risk for developing shoulder problems would most likely benefit from posttreatment physical therapy, currently, there is no gold standard for identifying this patient group. This is particularly important in low- and middle-income countries where scarce monetary resources need to be directed specifically to those most in need. Modulators of the angiogenesis pathway have been implicated in noncancer shoulder conditions such as rotator cuff disease, adhesive capsulitis, and tendon injuries. The present review summarizes the role of angiogenesis in the development of shoulder morbidity among breast cancer survivors and sets forth the rationale for our belief that angiogenesis signaling may help explain a proportion of the reported clinical variability noted in the development of shoulder pain and dysfunction and upper-limb lymphedema after breast cancer treatment.
\end{abstract}

Keywords: angiogenesis, shoulder dysfunction, cytokines, polymorphism, breast cancer therapy

\section{Introduction}

Among women, breast cancer is both the most common cause of cancer-related deaths and the most frequently diagnosed type of cancer ( $\sim 25 \%$ of all cancers) worldwide. ${ }^{1}$ The International Agency for Research on Cancer estimated 1.7 million new breast cancer cases among women worldwide in 2012, ${ }^{1,2}$ while in South Africa, an agestandardized incidence rate of 31.4 per 100,000 was estimated in 2011 as provided by the National Cancer Registry. ${ }^{3}$ More recent prevalence or incidence rates have not yet been established, either globally or in South Africa.

High 5-year survival rates of up to $89.2 \%$ have been reported following breast cancer treatment. ${ }^{4}$ Although generally lower in low-income countries, ${ }^{4}$ survival rates will most likely continue to rise due to advances in treatment, increased awareness, and early detection. Nevertheless, a significant proportion of breast cancer survivors experience upper extremity problems after treatment, which include pain, tightness, numbness, lymphedema, and limited range of motion, among others. ${ }^{5-9}$ Moreover, previous studies have suggested that shoulder morbidity after breast cancer treatment may
Correspondence: Delva Shamley Clinical Research Centre, Faculty of Health Sciences, University of Cape

Town, Anzio Rd, Observatory, 7925

Cape Town, South Africa

Email Delva.shamley@uct.ac.za 
persist longer than is commonly reported. ${ }^{5,10,11}$ Although substantial variability exists among previous reports, $20 \%-32 \%$ of breast cancer survivors report arm lymphedema and pain or dysfunction in the shoulder, arm, or breast at least 1 year after primary treatment. ${ }^{5,12-17}$ These side effects, especially at the shoulder or arm, reduce the functional use of the upper limb of affected patients, limiting their quality of life and ability to return to work. ${ }^{5,18,19}$ The shoulder girdle comprises joints (glenohumeral, acromioclavicular, and sternoclavicular joints), associated muscles, and connective tissue connecting the upper arm and shoulder area, providing a mechanism for upper-limb motion. Breast cancer treatment is believed to place survivors at risk of developing impaired resting shoulder girdle alignment. ${ }^{20}$ The altered shoulder movement patterns observed in breast cancer survivors mimic those seen in known general shoulder conditions such as rotator cuff disease and adhesive capsulitis. ${ }^{21}$ In fact, such diagnoses have been used to describe shoulder and arm morbidities in breast cancer survivors and have been associated with pain. ${ }^{20,22,23}$ It is believed that breast cancer treatment-related impairments of the shoulder complex place breast cancer survivors at risk of developing symptomatic rotator cuff disease..$^{20}$

There is substantial evidence supporting the effectiveness of different types of physical therapy in reducing upper-limb pain and lymphedema and improving shoulder range of motion (and, thus, shoulder function) in breast cancer survivors experiencing upper-limb morbidity. ${ }^{24-28}$ Nonetheless, the complex etiology of shoulder morbidity in breast cancer survivors has long been appreciated, with both treatment-related and patientrelated factors implicated. ${ }^{10,12,15,17,20,29-37}$ These factors include treatment type (e.g., type of surgery and the extent of lymph node surgery), time after treatment, disease characteristics, age, genetic factors, and the presence of comorbidities and other phenotypes such as high BMI. However, a large proportion of the variation in developing pain, and perhaps other morbidities as well, following breast cancer treatment still remains unexplained. ${ }^{31,38}$ For instance, Wang et al reviewed that absolute risk increases of only $3 \%-21 \%$ in developing persistent pain following breast cancer treatment can be explained from a total of 77 factors. ${ }^{31}$ Previous findings suggest that shoulder morbidity after breast cancer treatment is bilateral, ${ }^{10,30,36}$ and it has been shown that "structures unrelated to direct surgery and/or radiotherapy treatment are affected," ${ }^{39}$ suggesting a systemic cause. These collective findings suggest the need to focus on molecular signaling pathways.

Fibrogenic and inflammatory molecular signaling pathways have been implicated in the development of morbidity following breast cancer treatment as well as other forms of cancer. ${ }^{40-46}$ Although such signaling pathways constitute normal healing and repair processes, aberrant expression of signaling factors may underlie pathological processes such as persistent pain, swelling, and dysfunction of the shoulder complex reported among breast cancer survivors. According to the central dogma of molecular biology, it would follow that genetics may also be an important factor. Indeed, evidence suggesting specific single-nucleotide polymorphism (SNP)-modulated variation in inflammatory gene expression has been reported in studies on musculoskeletal pain following breast cancer treatment with aromatase inhibitors. ${ }^{47,48}$ Signaling pathways of inflammation, fibrosis, and angiogenesis have several links. In addition to fibrosis and inflammation, angiogenesis has been implicated in noncancer shoulder conditions such as rotator cuff disease ${ }^{49-51}$ and adhesive capsulitis. ${ }^{52}$ Angiogenesis has also been implicated in healing and adaptation pathways in noncancer musculoskeletal conditions such as tendon injuries ${ }^{53}$ and in the physiological response to mechanical loading. ${ }^{54,55}$ Evaluation of angiogenesis signaling factors in breast cancer survivors may, therefore, increase our understanding of the pathophysiology of upper-limb morbidities in this context and, perhaps, help explain a proportion of the variability in the development of such morbidities. In this review, we discuss the aspects of angiogenesis-related signaling factors as potential markers of risk for the development of shoulder morbidity after breast cancer treatment.

\section{Ethical approval}

The current review is part of an ongoing study approved by the Human Research Ethics Committee at the University of Cape Town, South Africa.

\section{Literature search and selection}

Database searches for articles and reviews were conducted in the following databases: PubMed, Scopus, Web of Science, MEDLINE, and CINAHL for articles published from January 1990 up to July 2016 using the following search terms: ("breast cancer" OR "breast carcinoma" OR "breast neoplasm*" OR "breast tumor") AND ("treatment" OR "therapy") AND ("shoulder pain" OR "shoulder dysfunction" OR "lymphoedema" OR "lymphedema" OR "range of motion") AND ("angiogenesis" OR "inflammat*"). A search was also conducted using the same terms excluding ("breast cancer" OR "breast carcinoma" OR "breast neoplasm*” OR "breast tumor") and ("treatment" OR "therapy") to capture articles implicating angiogenesis in general shoulder conditions independent of breast cancer treatment. The articles were 
narrowed down by analyzing the titles and then the abstracts. We retained articles and reviews on the pathophysiology of shoulder pain and dysfunction both in breast cancer survivors and in noncancer patients. Trials on the efficacy of treatment of shoulder pathology were excluded.

\section{Angiogenesis}

Angiogenesis, the formation of new blood vessels from the endothelium of existing vasculature, is a fundamental process that occurs in both physiological and pathophysiological situations. ${ }^{56}$ It is a complex process that results in the transition of an endothelial cell (EC) from a quiescent to angio-active phenotype, through the activation of vital cellular events including EC activation, proliferation, migration, survival, and extracellular matrix remodeling ${ }^{57}$ (Figure 1). Angiogenesis regulation involves two main transcription factors, nuclear factor $\kappa \mathrm{B}(\mathrm{NF}-\mathrm{\kappa B})$ and hypoxia-inducible factors (HIFs), in separate molecular pathways that induce expression of angiogenesis-associated signaling factors (cytokines, growth factors, and receptors). ${ }^{56}$ The transcription factor
NF- $\mathrm{KB}$ links angiogenesis and inflammation processes. ${ }^{56}$ Furthermore, inflammatory cells participate in the regulation of angiogenesis by secreting proinflammatory cytokines that directly or indirectly influence the activity of ECs. ${ }^{58}$

Vascular endothelial growth factor-A (VEGF-A), the main angiogenesis signaling factor, stimulates EC proliferation, survival, and migration, mainly through its receptor VEGF-R2 (also known as KDR; Figure 1). ${ }^{56,57}$ Matrix metalloproteinases (MMPs) catalyze the proteolytic degradation of the basement membrane, which precedes EC migration, and their activity is regulated by tissue inhibitors of metalloproteinases (TIMPs) ${ }^{57}$ Thrombospondins (THBS- 1 or -2) mediate antiangiogenic effects through the suppression of VEGF-A bioavailability and the inhibition of its activity through KDR. ${ }^{59}$ VEGF-A signaling through KDR upregulates some MMPs and endothelial nitric oxide synthase (eNOS), and the later catalyzes nitric oxide (NO) production which stimulates vascular permeability, an essential event in angiogenesis. ${ }^{60,61}$ The adhesion molecules vascular cell adhesion molecules (VCAMs) and intercellular adhesion molecules,

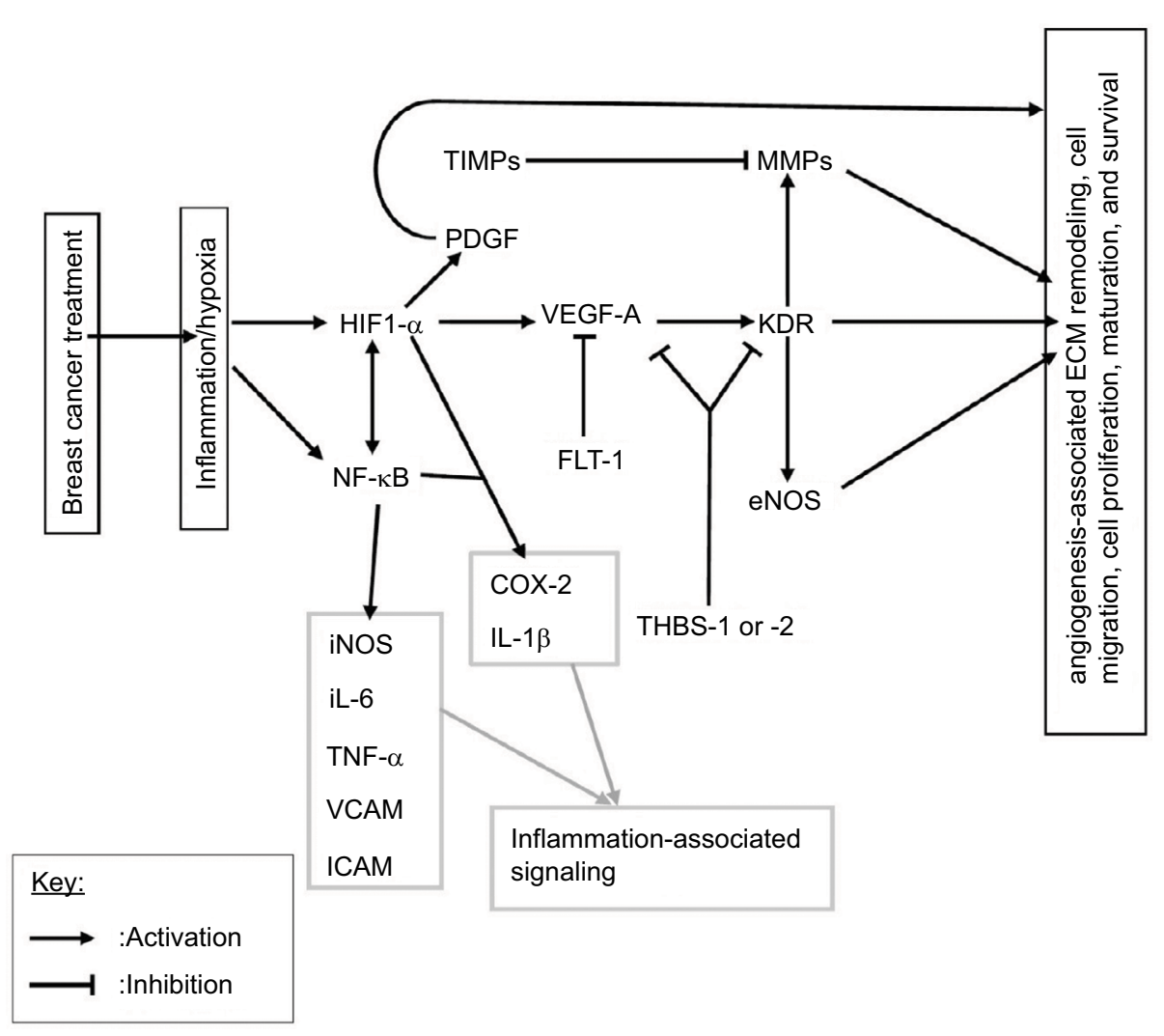

Figure I A schematic representation of angiogenesis signaling and suggested links to breast cancer therapy, inflammatory signaling, and matrix remodeling.

Notes: Breast cancer treatments, especially radiotherapy and chemotherapy, are known to induce an inflammatory response and resultant hypoxia in the tissue microenvironment. This response activates the two main transcription factors involved in angiogenesis regulation, NFKB and HIFI- $\alpha$, which in turn activate angiogenesis signaling. Angiogenesis is largely regulated by the main factor VEGF-A and its receptor KDR, which induce the activation, proliferation, migration, survival, and maturation of endothelial cells.

Abbreviations: ECM, extracellular matrix; eNOS, endothelial nitric oxide synthase; HIF, hypoxia-inducible factor; ICAM, intercellular adhession molecule; MMPs, matrix metalloproteinases; NF- $\kappa B$, nuclear factor $\kappa B$; PDGF, platelet-derived growth factor; THBS, thrombospondins; TIMPs, tissue inhibitors of metalloproteinases; TNF- $\alpha$, tumor necrosis factor-alpha; VCAM, vascular cell adhesion molecule; VEGF-A, vascular endothelial growth factor-A. 
which mediate leukocyte infiltration, are also important components of angiogenesis. ${ }^{62,63}$ VEGFR-1 also known as FLT-1, with its relatively higher affinity for VEGF-A and weak tyrosine kinase activity, is believed to reduce VEGF-A bioavailability to the main angiogenesis signaling receptor, $\mathrm{KDR}$, and is therefore antiangiogenic. ${ }^{57,64}$ Even though the links to angiogenesis are not included, for simplicity, it is noteworthy that the proinflammatory cytokines IL-1 $\beta$, IL-6, and tumor necrosis factor-alpha (TNF- $\alpha$ ) also possess proangiogenic effects and can transcriptionally be activated by HIF or NF- $\kappa B^{56,58}$ (Figure 1).

The direct determination of angiogenesis involves investigation of changes in microvessel density, which may be done using ultrasound examination or immunohistochemistry of tissue biopsies. However, angiogenesis-related factors may provide useful information regarding angiogenic potential. The occurrence of angiogenesis depends on the balance between proangiogenic and antiangiogenic molecules in the tissue microenvironment ${ }^{65}$ (Table 1). Upregulation of proangiogenic factors promotes angiogenesis by facilitating the migration, proliferation, and differentiation of ECs into newly formed capillaries that can subsequently develop into more mature vessels. ${ }^{57,65}$ The HIF and NF- $\mathrm{KB}$ signaling pathways crossregulate each other, ${ }^{56,57}$ and in effect, the HIF pathway can be induced in nonhypoxic conditions such as in response to reactive oxygen species (ROS) and NO. ${ }^{56}$ Angiogenesis is also regulated by microRNAs, which either upregulate or downregulate specific components of the angiogenesis pathway. ${ }^{56,66}$

\section{Role of angiogenesis in response to breast cancer treatment}

Angiogenesis is, at least to some extent, involved in the physiological response of the tumor microenvironment, or surrounding tissue, to breast cancer treatment, especially the common adjuvant treatments radiotherapy and chemotherapy. Moreover, an imbalance of or changes in inflammatory

Table I Examples of proangiogenic and antiangiogenic factors

\begin{tabular}{ll}
\hline Proangiogenic & Antiangiogenic \\
\hline VEGF-A & Thrombospondins (TSP-I and TSP-2) \\
PDGF & Angiostatin \\
SDF & IL- 12 \\
bFGF & Angiopoietin 2 \\
TNF- $\alpha$ & Endostatin \\
IL-8 & Interferon- $\alpha,-\beta$, and $-\gamma$ \\
NRP-I & FLT-I \\
\hline
\end{tabular}

Abbreviations: bFGF, basic fibroblast growth factor; IL, interleukin; NRP-I, neuropilin- I; PDGF, platelet-derived growth factor; TNF- $\alpha$, tumor necrosis factoralpha; VEGF-A, vascular endothelial growth factor-A. angiogenesis-related cytokines (ARCs) have been demonstrated in breast cancer patients after treatment. ${ }^{67,68}$ For example, De Sanctis et al reported significant increases in levels of interleukins (IL[s]) IL-1 $\beta$, IL-2, and IL-6 and TNF- $\alpha 4$ weeks after adjuvant radiation therapy, particularly in patients presenting with fatigue. ${ }^{67}$ Although some angiogenesis signaling factors are immobilized by various means such as binding to extracellular matrix components, some are soluble and thus capable of mediating systemic effects. This may particularly be important in the development of morbidity among breast cancer survivors since it has been shown that structures outside the direct treatment field are also affected. ${ }^{39}$

\section{Radiotherapy and angiogenesis}

Radiotherapy involves exposure of the tumor site to a specific dose of ionizing radiation, usually given in fractions. More than $50 \%$ of early stage breast cancer patients receive radiation therapy either alone or as an adjuvant treatment. ${ }^{69}$ Ionizing radiation damages DNA, which induces an intracellular response that leads to death by apoptosis in susceptible cells. $^{70}$ Rapid proliferating cells, such as tumor cells, are particularly sensitive to ionizing radiation but DNA damage is also induced in normal tissue, including ECs, due to the indiscriminate nature of the treatment. ${ }^{41}$ Ionizing radiation also acts indirectly through the generation of ROS and reactive nitrogen species which, in addition to damaging DNA, inhibit cellular enzymes. ${ }^{70,71}$ Consequently, when the cell's antioxidant and DNA repair capacities are overwhelmed, cell death by apoptosis occurs..$^{70,71}$

The DNA damage from irradiation elicits a biological response in the tumor microenvironment, which involves the release of chemokines, cytokines, and adhesion molecules leading to altered cell-cell interactions and the influx of inflammatory cells, particularly in ECs of tumor and/or normal tissue. ${ }^{41,72,73}$ These mediators are involved in various molecular pathways including angiogenesis, and they may participate in the development of normal tissue damage characteristic of either early (occurring in $<6$ months after irradiation) or late (occurring in $\geq 6$ months after irradiation) radiation toxicity effects. ${ }^{74,75}$ Radiation also induces soft tissue fibrosis, which can cause stiffness in the shoulder girdle leading to reduced range of motion..$^{20,40}$ Fibrosis is also linked to angiogenesis through its main signaling factor, transforming growth factor-beta (TGF- $\beta$ ), which can influence angiogenesis. ${ }^{57}$

One of the late toxicity effects of radiation therapy is damage to the vascular system in the form of lesions, which 
may occur months to several years after treatment. ${ }^{42}$ The microvessels (i.e., capillaries) appear to be the most sensitive to lesions, and the damage culminates in thrombosis, necrosis, capillary rupture, or even loss of entire capillary segments. ${ }^{42}$ The physiological response to vascular damage is the activation of the angiogenesis pathway. There are several ways in which radiotherapy-induced vascular damage can promote angiogenesis. The resultant hypoxia is, in itself, a trigger for angiogenesis. Inflammatory cells attracted to the site of radiation damage can potentiate angiogenesis by secreting inflammatory cytokines that have proangiogenic signals such as TNF- $\alpha$, IL-1 $\beta$, and IL- 6 or angiogenesis factors such as VEGF. For example, macrophages have been shown to enhance their expression of VEGF-A and release NO, a stabilizer of HIF-1, in response to irradiation. ${ }^{76}$ Radiation has also been shown to reduce the expression of antiangiogenic factors at low doses. ${ }^{76}$ As a result, there is ongoing research on the co-use of antiangiogenic drugs to increase effectiveness of radiotherapy in cancer treatment. ${ }^{72,76}$

Clearly, there are conflicting findings on the effect of irradiation on angiogenesis, ${ }^{41,73,77}$ and it has been suggested that the effects are dose and time dependent. ${ }^{76}$ Sofia Vala et al reported that low-dose ionizing radiation promotes EC migration and, in harmony with their findings, they demonstrated that low-dose ionizing radiation promotes tumor growth and metastasis using murine experimental models of leukemia and orthotopic breast cancer. ${ }^{73}$ Plausibly, the same effect on angiogenesis can be expected given the low doses that characterize conventional fractionated radiotherapy.

\section{Chemotherapy and angiogenesis}

Many different types of chemotherapy drugs administered in various combinations are used to treat breast cancer. In a curative setting, cytotoxic drugs are usually given as an adjuvant (i.e., in addition to surgery and/or radiotherapy) for primary breast cancer to reduce the risk of recurrence. Chemotherapy can also be given in a neoadjuvant setting to shrink the tumor. Although there are many different types of mechanistically distinct chemotherapy drugs, there are general side effects associated with most of them such as fatigue, joint pain, depression, mouth ulcers, hair loss, and myalgia. ${ }^{45}$ However, there appears to be an involvement of cytokines in the development of these symptoms, although cytokine profiles may vary with the type of drug. ${ }^{45,68,78}$

Taxanes have been shown to have intratumoral antiangiogenic effects in murine models of breast cancer. ${ }^{79}$ Although intratumoral effects on angiogenesis are less relevant to breast cancer survivors, after tumor resection, this demonstrates the potential of some chemotherapy drugs to influence angiogenesis. Furthermore, given the integrated approach that characterizes conventional breast cancer treatment, there may be augmentation of angiogenesis stimuli. Wood et al suggested that several mechanistically distinct chemotherapy drugs share a common ability to activate the enzyme p38 mitogen-activated protein kinase (p38 MAPK), which induces expression of proinflammatory cytokines such as TNF- $\alpha$, IL- $1 \beta$, and IL- $6 .{ }^{45}$ Elevated levels of cytokines such as TNF- $\alpha$, IL-6, IL-8, and IL-10 have been reported in cancer patients undergoing conventional chemotherapy. ${ }^{80-82}$ It is noteworthy that these cytokines are also associated with angiogenesis.

\section{Potential role in healing and adaptation pathways}

Owing to their roles in cellular proliferation, survival, migration, chemotaxis, matrix remodeling, blood vessel formation, and links to other molecular pathways such as inflammation, ARCs and growth factors may play a role in healing and adaptation pathways after treatment. Angiogenesis-related growth factors such as basic fibroblast growth factor (bFGF), platelet-derived growth factor (PDGF), and insulin-like growth factor-1 are believed to participate in rotator cuff tendon healing. ${ }^{53}$ Genes encoding angiogenesis-related signaling factors such as VEGF have been shown to be involved in the response of tendon cells and cartilage discs to mechanical loading. ${ }^{54,55}$ Previous findings suggest a compensatory angiogenesis in lymphedema. ${ }^{83}$ It would follow that the development of shoulder/arm pain, lymphedema, and dysfunction after treatment may, perhaps, be a result of failed healing. Aberrant angiogenesis signaling may lead to abnormal cell-cell interactions, nonoptimal angiogenesis, and impairments in matrix remodeling, which collectively compromises tissue healing.

\section{Potential role in pain, inflammation, and dysfunction}

Angiogenesis-related signaling factors such as IL-1 $\beta$, IL-6, TNF- $\alpha$, and COX-2 are known to contribute to pain hypersensitivity by inducing the production of prostaglandins and other proalgesic agents, which activate nociceptors..$^{84} \mathrm{Lymph}$ node dissection can lead to lymphedema by compromising the lymphatic system's ability to return interstitial fluid to main circulation, which is important in the resolution of inflammation. However, pro-inflammatory ARCs such as IL-1 $\beta$, IL-6, and TNF- $\alpha$ have the potential to aggravate lymphedema by enhancing inflammation. Some angiogenesis-related factors 
are involved in extracellular matrix remodeling (Figure 1). Abnormal collagen and matrix production can potentially contribute to stiffness in the shoulder joint capsule, ${ }^{85}$ which can lead to reductions in the range of motion.

\section{Implication in noncancer general shoulder conditions}

Previous studies suggest the importance of angiogenesis in noncancer musculoskeletal conditions of the shoulder such as tendon injuries, ${ }^{53}$ adhesive capsulitis, ${ }^{52}$ and rotator cuff disease ${ }^{51,86-88}$ For example, such studies have demonstrated altered vascularity or potential to heal as determined from fibroblast cellularity, vascularity, and the presence of a significant inflammatory component in rotator cuff tears. ${ }^{86-88}$ Moreover, previous studies have demonstrated altered expression of ARCs in such noncancer general musculoskeletal conditions of the shoulder. ${ }^{51,52,85,89,90}$ For example, altered levels of cytokines including IL-1 $\beta$, IL- 8 , and VEGF have been shown in rotator cuff disease, ${ }^{51}$ whereas IL- $1 \beta$, TNF- $\alpha$, PDGF, and TGF- $\beta$ were implicated in the pathogenesis of adhesive capsulitis. $^{52}$

\section{Genetic aspects}

Evidence of a potential genetic component in the development of posttreatment morbidity in breast cancer survivors has been explored and reported in several studies. ${ }^{34,35,44,47,91-93}$ Most of these studies involved associations between gene polymorphisms with clinical outcomes such as lymphedema, breast pain, fatigue, and anxiety, covering a total of 17 SNPs and 4 haplotypes from 14 genes $^{34,35,44,47,91-93}$ (Table 2). However, replication of these findings has not been achieved, largely due to methodological issues among the studies which include, but are not limited to, variations in population structure and size, and heterogeneity in follow-up periods (or period after surgery) and outcome measures. Moreover, to date, these studies ${ }^{34,35,44,47,91-93}$ have largely focused on inflammatory gene polymorphisms, with one exception. ${ }^{34}$ Clearly, angiogenesis is unexplored even though evidence shows it is linked to inflammation. Associations were reported for both increased and decreased risks of morbidity (Table 2). For example, one study reported an association between persistent breast pain following breast cancer surgery and a polymorphism within $I L-1$ receptor type 2 (IL1-R2 rs1,16,74,595 T>C) and also highlighted a haplotype, implicating the $3^{\prime}$ untranslated region within $I L-10{ }^{35}$ In another study, an association between a polymorphism in NFKB2 gene and the risk of developing lymphedema after breast cancer treatment was reported. ${ }^{44}$ With the exception of lymphedema, the clinical outcomes these studies focused on were not shoulder complex-specific outcomes such as

Table 2 Genes and SNPs that have been reported to be significantly associated with morbidity after breast cancer treatment

\begin{tabular}{|c|c|c|c|c|}
\hline Gene & SNP/haplotype & Association & Risk & Study \\
\hline FOXC2 & haplotype A03 & Lymphedema & $\downarrow$ & Miaskowski et $\mathrm{al}^{93}$ \\
\hline$I L I B$ & rs 16,944 & Fatigue & $\uparrow$ & Collado-Hidalgo et a $\left.\right|^{91}$ \\
\hline ILIR2 & rsI,I6,74,595 & Severe persistent breast pain & $\uparrow$ & Stephens et $\mathrm{al}^{35}$ \\
\hline IL4 & rs $22,27,284$ & Lymphedema & $\downarrow$ & Leung et $\mathrm{al}^{44}$ \\
\hline IL6 & rs $18,00,795$ & Fatigue & $\uparrow$ & Bower et a $^{92}$ \\
\hline \multirow[t]{2}{*}{ ILIO } & $\mathrm{rs} \mid 5,18,1 \mathrm{II}$ & Lymphedema & $\downarrow$ & Leung et $\mathrm{al}^{44}$ \\
\hline & haplotype A8 & Severe persistent breast pain & $\downarrow$ & Stephens et $\mathrm{a}^{35}$ \\
\hline LCP2 & rs $3,|5,72|$ & Lymphedema & $\downarrow$ & Miaskowski et $\mathrm{al}^{93}$ \\
\hline NFKB2 & $\mathrm{rs} 10,56,890$ & Lymphedema & $\uparrow$ & Leung et $\mathrm{al}^{44}$ \\
\hline \multirow[t]{2}{*}{ NRP2 } & rs8,49,530 & Lymphedema & $\downarrow$ & Miaskowski et $\mathrm{al}^{93}$ \\
\hline & haplotype FOI & & & \\
\hline SYK & rsI, 58,689 & Lymphedema & $\uparrow$ & Miaskowski et $\mathrm{al}^{93}$ \\
\hline \multirow[t]{4}{*}{ TCLIA* } & rs7।,58,782 & Musculoskeletal adverse events & $\uparrow$ & Ingle et $\mathrm{a}^{47}$ \\
\hline & rs7।,59,7I3 & & & \\
\hline & rs $23,69,049$ & & & \\
\hline & rsI, I8,49,538 & & & \\
\hline \multirow[t]{3}{*}{ TNFA } & rs $18,00,629$ & Fatigue & $\uparrow$ & Bower et $\mathrm{a}^{92}$ \\
\hline & rs $17,99,964$ & Higher anxiety levels & $\downarrow$ & Miaskowski et $\mathrm{al}^{93}$ \\
\hline & rs 30,93,662 & & $\uparrow$ & \\
\hline VCAMI & rs31,76,86I & Lymphedema & $\downarrow$ & Miaskowski et $\mathrm{a}^{93}$ \\
\hline VEGFC & haplotype B03 & & $\downarrow$ & \\
\hline
\end{tabular}

Notes: TCLIA* gene implied due to proximity to the SNPs (all SNPs were [926-7000 bp]) proximal to the TCLIA gene. $\uparrow$, increase; $\downarrow$, decrease.

Abbreviations: NF- $\mathrm{KB}$, nuclear factor $\mathrm{\kappa B}$; SNP, single-nucleotide polymorphism; TCLIA, T-cell leukemia IA; VCAM, vascular cell adhesion molecules. 
movement-related pain or dysfunction, which are known to reduce quality of life..$^{34,35,44,47,91-93}$ There are indications of a genetic component in the development of noncancer musculoskeletal shoulder conditions, evident from the predisposition of siblings to develop rotator cuff disease or rotator cuff tears. ${ }^{49,94,95}$ In support of this, associations between several polymorphisms and risk of developing rotator cuff disease have been reported. ${ }^{96}$ Furthermore, previous studies have reported associations between polymorphisms in various genes including genes encoding collagen and angiogenesis-related factors and risks of musculoskeletal injuries in sport. ${ }^{97-100}$ These factors are components of matrix remodeling, which is linked to angiogenesis.

\section{Conclusion and knowledge gaps}

Angiogenesis is potentially involved in the etiology of shoulder pain, lymphedema, and dysfunction and may help explain a proportion of the interindividual variability in the development of such morbidity among breast cancer survivors. It is involved in the response of the tissue microenvironment to adjuvant cancer therapies and has potential roles in pain, lymphedema, and dysfunction pathways. Furthermore, angiogenesis has been shown to play a role in noncancer shoulder conditions such as rotator cuff disease. ${ }^{86-88}$ However, there is a paucity of relevant studies investigating its role in morbidity after breast cancer treatment. Although several studies have explored expression profiles of cytokines and growth factors in breast cancer patients, most of these have focused on a few clinical symptoms such as cognitive impairments, fatigue, and breast pain or general pain. ${ }^{67,68,78,80,81,101,102}$ Clearly, most of these symptoms do not reside at the shoulder complex, the site most associated with limitations in daily activities. In addition, most focus has been on inflammatory cytokines with one exception. ${ }^{34}$ Similarly, with one exception, ${ }^{34}$ candidate genetic associations have largely focused on polymorphisms in inflammatory cytokine genes. Indeed, the role of angiogenesis signaling in the development of shoulder complex morbidity after breast cancer treatment is unexplored despite that it is linked to inflammation. Therefore, there is a need to explore and characterize the potential of angiogenesisassociated signaling factors in explaining interindividual variability in the development of posttreatment morbidity in breast cancer survivors. It is noteworthy that most of the studies that explored signaling factors in posttreatment morbidities, ${ }^{67,68,78,80,81,101,102}$ with one exception, ${ }^{101}$ involved a relatively short follow-up period (or period after surgery), up to 6 months after treatment, whereas current evidence suggests that shoulder/arm morbidity in breast cancer patients can persist for up to 6 years or more after surgery. ${ }^{10,11}$
Molecular signaling pathways or symptoms may evolve over time, and there is a need for longer follow-up periods (or period after surgery) to investigate this phenomenon.

\section{Acknowledgments}

We acknowledge the financial assistance of the South African National Research Foundation (NRF) toward this research. Opinions expressed and conclusions arrived at, are those of the authors and are not necessarily to be attributed to the NRF.

\section{Disclosure}

The authors report no conflicts of interest in this work.

\section{References}

1. WHO. Latest World Cancer Statistics. Geneva: World Health Organization; 2013. 12 December 2013. Available from: https://www.iarc.fr/en/ media-centre/pr/2013/pdfs/pr223_E.pdf. Accessed December 07, 2017.

2. Torre LA, Bray F, Siegel RL, Ferlay J, Lortet-Tieulent J, Jemal A Global cancer statistics, 2012. CA Cancer J Clin. 2015;65(2):87-108.

3. National Cancer Registry Report 2011. Cancer in South Africa 2011 Full Report. National Health Laboratory Service. 2016:43. Available from: http://www.cansa.org.za/files/2016/08/NCR-2011-cancer-tables. pdf. Accessed May 15, 2017.

4. Youlden DR, Cramb SM, Dunn NA, Muller JM, Pyke CM, Baade PD. The descriptive epidemiology of female breast cancer: an international comparison of screening, incidence, survival and mortality. Cancer Epidemiol. 2012;36(3):237-248.

5. Hayes SC, Johansson K, Stout NL, et al. Upper-body morbidity after breast cancer: incidence and evidence for evaluation, prevention, and management within a prospective surveillance model of care. Cancer. 2012;118(8 Suppl):2237-2249.

6. Hayes SC, Rye S, Battistutta D, DiSipio T, Newman B. Upper-body morbidity following breast cancer treatment is common, may persist longer-term and adversely influences quality of life. Health Qual Life Outcomes. 2010;8:92.

7. Dean LT, DeMichele A, LeBlanc M, et al. Black breast cancer survivors experience greater upper extremity disability. Breast Cancer Res Treat. 2015;154(1):117-125.

8. Feiten S, Dunnebacke J, Heymanns J, et al. Breast cancer morbidity: questionnaire survey of patients on the long term effects of disease and adjuvant therapy. Dtsch Arztebl Int. 2014;111(31-32):537-544.

9. Johansen S, Fossa K, Nesvold IL, Malinen E, Fossa SD. Arm and shoulder morbidity following surgery and radiotherapy for breast cancer. Acta Oncol. 2014;53(4):521-529.

10. Shamley D, Lascurain-Aguirrebena I, Oskrochi R, Srinaganathan R. Shoulder morbidity after treatment for breast cancer is bilateral and greater after mastectomy. Acta Oncol. 2012;51(8):1045-1053.

11. Schmitz KH, Speck RM, Rye SA, DiSipio T, Hayes SC. Prevalence of breast cancer treatment sequelae over 6 years of follow-up: the Pulling Through Study. Cancer. 2012;118(8 Suppl):2217-2225.

12. Togawa K, Ma H, Sullivan-Halley J, et al. Risk factors for self-reported arm lymphedema among female breast cancer survivors: a prospective cohort study. Breast Cancer Res: BCR. 2014;16(4):414.

13. Yen TW, Fan X, Sparapani R, Laud PW, Walker AP, Nattinger AB. A contemporary, population-based study of lymphedema risk factors in older breast cancer women. Ann Surg Oncol. 2009;16(4):979-988.

14. Peuckmann V, Ekholm O, Rasmussen NK, et al. Chronic pain and other sequelae in long-term breast cancer survivors: nationwide survey in Denmark. Eur J Pain. 2009;13(5):478-485.

15. Miaskowski C, Paul SM, Cooper B, et al. Identification of patient subgroups and risk factors for persistent arm/shoulder pain following breast cancer surgery. Eur J Oncol Nurs. 2014;18(3):242-253. 
16. Gartner R, Jensen MB, Nielsen J, Ewertz M, Kroman N, Kehlet H. Prevalence of and factors associated with persistent pain following breast cancer surgery. JAMA. 2009;302(18):1985-1992.

17. Hidding JT, Beurskens CH, van der Wees PJ, van Laarhoven HW, Nijhuis-van der Sanden MW. Treatment related impairments in arm and shoulder in patients with breast cancer: a systematic review. PLoS One. 2014;9(5):e96748.

18. Nesvold IL, Reinertsen KV, Fossa SD, Dahl AA. The relation between arm/shoulder problems and quality of life in breast cancer survivors: a cross-sectional and longitudinal study. J Cancer Surviv. 2011;5(1):62-72.

19. Nesvold IL, Fossa SD, Holm I, Naume B, Dahl AA. Arm/shoulder problems in breast cancer survivors are associated with reduced health and poorer physical quality of life. Acta Oncol. 2010;49(3):347-353.

20. Ebaugh D, Spinelli B, Schmitz KH. Shoulder impairments and their association with symptomatic rotator cuff disease in breast cancer survivors. Med Hypotheses. 2011;77(4):481-487.

21. Shamley D, Srinaganathan R, Oskrochi R, Lascurain-Aguirrebena I, Sugden E. Three-dimensional scapulothoracic motion following treatment for breast cancer. Breast Cancer Res Treat. 2009;118(2):315-322.

22. Stubblefield MD, Custodio CM. Upper-extremity pain disorders in breast cancer. Arch Phys Med Rehabil. 2006;87(3 Suppl 1):S96-S99.

23. Stubblefield MD, Keole N. Upper body pain and functional disorders in patients with breast cancer. PMR. 2014;6(2):170-183.

24. Tatham B, Smith J, Cheifetz O, et al. The efficacy of exercise therapy in reducing shoulder pain related to breast cancer: a systematic review. Physiother Can. 2013;65(4):321-330.

25. Galantino ML, Stout NL. Exercise interventions for upper limb dysfunction due to breast cancer treatment. Phys Ther. 2013;93(10):1291-1297.

26. McNeely ML, Campbell K, Ospina M, et al. Exercise interventions for upper-limb dysfunction due to breast cancer treatment. Cochrane Database Syst Rev. 2010(6):CD005211.

27. Loh SY, Musa AN. Methods to improve rehabilitation of patients following breast cancer surgery: a review of systematic reviews. Breast Cancer (Dove Med Press). 2015;7:81-98.

28. De Groef A, Van Kampen M, Dieltjens E, et al. Effectiveness of postoperative physical therapy for upper-limb impairments after breast cancer treatment: a systematic review. Arch Phys Med Rehabil. 2015;96(6):1140-1153.

29. Nesvold IL, Dahl AA, Lokkevik E, Marit Mengshoel A, Fossa SD. Arm and shoulder morbidity in breast cancer patients after breast-conserving therapy versus mastectomy. Acta Oncol. 2008;47(5):835-842.

30. Sagen A, Kaaresen R, Sandvik L, Thune I, Risberg MA. Upper limb physical function and adverse effects after breast cancer surgery: a prospective 2.5-year follow-up study and preoperative measures. Arch Phys Med Rehabil. 2014;95(5):875-881.

31. Wang L, Guyatt GH, Kennedy SA, et al. Predictors of persistent pain after breast cancer surgery: a systematic review and meta-analysis of observational studies. CMAJ. 2016;188(14):E352-E361.

32. Johansen S, Foss K, Nesvold IL, Malinen E, Foss SD. Arm and shoulder morbidity following surgery and radiotherapy for breast cancer. Acta Oncol. 2014;53(4):521-529.

33. Dahl AA, Nesvold IL, Reinertsen KV, Fossa SD. Arm/shoulder problems and insomnia symptoms in breast cancer survivors: cross-sectional, controlled and longitudinal observations. Sleep Med. 2011;12(6):584-590.

34. Miaskowski C, Dodd M, Paul SM, et al. Lymphatic and angiogenic candidate genes predict the development of secondary lymphedema following breast cancer surgery. PLoS One. 2013;8(4):e60164.

35. Stephens K, Cooper BA, West C, et al. Associations between cytokine gene variations and severe persistent breast pain in women following breast cancer surgery. J Pain. 2014;15(2):169-180.

36. Adriaenssens N, Vinh-Hung V, Miedema G, et al. Early contralateral shoulder-arm morbidity in breast cancer patients enrolled in a randomized trial of post-surgery radiation therapy. Breast Cancer (Auckl). 2012;6:79-93.

37. DiSipio T, Rye S, Newman B, Hayes S. Incidence of unilateral arm lymphoedema after breast cancer: a systematic review and metaanalysis. Lancet Oncol. 2013;14(6):500-515.
38. Bell RJ, Robinson PJ, Nazeem F, et al. Persistent breast pain 5 years after treatment of invasive breast cancer is largely unexplained by factors associated with treatment. J Cancer Surviv. 2014;8(1):1-8.

39. Shamley DR, Srinanaganathan R, Weatherall R, et al. Changes in shoulder muscle size and activity following treatment for breast cancer. Breast Cancer Res Treat. 2007;106(1):19-27.

40. Straub JM, New J, Hamilton CD, Lominska C, Shnayder Y, Thomas SM. Radiation-induced fibrosis: mechanisms and implications for therapy. J Cancer Res Clinical Oncol. 2015;141(11):1985-1994.

41. Baeten CI, Castermans K, Lammering G, et al. Effects of radiotherapy and chemotherapy on angiogenesis and leukocyte infiltration in rectal cancer. Int J Radiat Oncol Biol Phys. 2006;66(4):1219-1227.

42. Fajardo LF. The pathology of ionizing radiation as defined by morphologic patterns. Acta Oncol. 2005;44(1):13-22.

43. Panis C, Pavanelli WR. Cytokines as mediators of pain-related process in breast cancer. Mediators Inflamm. 2015;2015:129034.

44. Leung G, Baggott C, West C, et al. Cytokine candidate genes predict the development of secondary lymphedema following breast cancer surgery. Lymphat Re Biol. 2014;12(1):10-22.

45. Wood LJ, Nail LM, Gilster A, Winters KA, Elsea CR. Cancer chemotherapy-related symptoms: evidence to suggest a role for proinflammatory cytokines. Oncol Nurs Forum. 2006;33(3):535-542.

46. Di Maggio FM, Minafra L, Forte GI, et al. Portrait of inflammatory response to ionizing radiation treatment. J Inflamm (Lond). 2015;12:14.

47. Ingle JN, Schaid DJ, Goss PE, et al. Genome-wide associations and functional genomic studies of musculoskeletal adverse events in women receiving aromatase inhibitors. J Clin Oncol. 2010;28(31): 4674-4682.

48. Liu M, Wang L, Bongartz T, et al. Aromatase inhibitors, estrogens and musculoskeletal pain: estrogen-dependent T-cell leukemia 1A (TCL1A) gene-mediated regulation of cytokine expression. Breast Cancer Res. 2012;14(2):R41.

49. Longo UG, Berton A, Papapietro N, Maffulli N, Denaro V. Epidemiology, genetics and biological factors of rotator cuff tears. Med Sport Sci. 2012;57:1-9.

50. Hegedus EJ, Cook C, Brennan M, Wyland D, Garrison JC, Driesner D. Vascularity and tendon pathology in the rotator cuff: a review of literature and implications for rehabilitation and surgery. Br J Sports Med. 2010;44(12):838-847.

51. Savitskaya YA, Izaguirre A, Sierra L, et al. The effect of angiogenesisrelated cytokine profiles on rotator cuff disease: discovery of new biomarkers of early tendon degeneration (SS-19). JArthroscopic Relat Surg. 2011;27(5 Suppl):e39.

52. Rodeo SA, Hannafin JA, Tom J, Warren RF, Wickiewicz TL. Immunolocalization of cytokines and their receptors in adhesive capsulitis of the shoulder. J Orthop Res. 1997;15(3):427-436.

53. Oliva F, Via AG, Maffulli N. Role of growth factors in rotator cuff healing. Sports Med Arthrosc. 2011;19(3):218-226.

54. Pufe T, Lemke A, Kurz B, et al. Mechanical overload induces VEGF in cartilage discs via hypoxia-inducible factor. Am J Pathol. 2004;164(1):185-192.

55. Mousavizadeh R, Duronio V, McCormack B, Khosravi S, Scott A. Mechanical loading modulates angiogenic factors in tendon cells. $\mathrm{Br}$ J Sports Med. 2013;47(9):e2.

56. Szade A, Grochot-Przeczek A, Florczyk U, Jozkowicz A, Dulak J. Cellular and molecular mechanisms of inflammation-induced angiogenesis. IUBMB Life. 2015;67(3):145-159.

57. Carmeliet $P$, Jain RK. Molecular mechanisms and clinical applications of angiogenesis. Nature. 2011;473(7347):298-307.

58. Naldini A, Carraro F. Role of inflammatory mediators in angiogenesis. Curr Drug Targets Inflamm Allergy. 2005;4(1):3-8.

59. Lawler PR, Lawler J. Molecular basis for the regulation of angiogenesis by thrombospondin-1 and -2. Cold Spring Harbor Perspect Med. 2012;2(5):a006627.

60. Funahashi Y, Shawber CJ, Sharma A, Kanamaru E, Choi YK, Kitajewski J. Notch modulates VEGF action in endothelial cells by inducing matrix metalloprotease activity. Vasc Cell. 2011;3(1):2. 
61. Kroll J, Waltenberger J. VEGF-A induces expression of eNOS and iNOS in endothelial cells via VEGF receptor-2 (KDR). Biochem Biophys Res Commun. 1998;252(3):743-746.

62. Schlesinger M, Bendas G. Vascular cell adhesion molecule-1 (VCAM-1)an increasing insight into its role in tumorigenicity and metastasis. Int $J$ Cancer. 2015;136(11):2504-2514.

63. Huang MT, Mason JC, Birdsey GM, et al. Endothelial intercellular adhesion molecule (ICAM)-2 regulates angiogenesis. Blood. 2005;106(5):1636-1643.

64. Shibuya M. Vascular endothelial growth factor (VEGF) and its receptor (VEGFR) signaling in angiogenesis: a crucial target for anti- and pro-angiogenic therapies. Genes Cancer. 2011;2(12):1097-1105.

65. Eichhorn ME, Kleespies A, Angele MK, Jauch KW, Bruns CJ. Angiogenesis in cancer: molecular mechanisms, clinical impact. Langenbecks Arch Surg. 2007;392(3):371-379.

66. Buysschaert I, Schmidt T, Roncal C, Carmeliet P, Lambrechts D. Genetics, epigenetics and pharmaco-(epi)genomics in angiogenesis. J Cell Mol Med. 2008;12(6B):2533-2551.

67. De Sanctis V, Agolli L, Visco V, et al. Cytokines, fatigue, and cutaneous erythema in early stage breast cancer patients receiving adjuvant radiation therapy. Biomed Res Int. 2014;2014:523568.

68. Janelsins MC, Mustian KM, Palesh OG, et al. Differential expression of cytokines in breast cancer patients receiving different chemotherapies: implications for cognitive impairment research. Support Care Cancer. 2012;20(4):831-839.

69. DeSantis CE, Lin CC, Mariotto AB, et al. Cancer treatment and survivorship statistics, 2014. CA Cancer J Clin. 2014;64(4): 252-271.

70. Baskar R, Dai J, Wenlong N, Yeo R, Yeoh KW. Biological response of cancer cells to radiation treatment. Front Mol Biosci. 2014;1:24.

71. Miao L, Holley AK, Zhao Y, St Clair WH, St Clair DK. Redox-mediated and ionizing-radiation-induced inflammatory mediators in prostate cancer development and treatment. Antioxid Redox Signal. 2014;20(9): $1481-1500$.

72. Martin BJ. Inhibiting vasculogenesis after radiation: a new paradigm to improve local control by radiotherapy. Semin Radiat Oncol. 2013;23(4):281-287.

73. Sofia Vala I, Martins LR, Imaizumi N, et al. Low doses of ionizing radiation promote tumor growth and metastasis by enhancing angiogenesis. PLoS One. 2010;5(6): 11222.

74. Bentzen SM. Preventing or reducing late side effects of radiation therapy: radiobiology meets molecular pathology. Nat Rev Cancer. 2006;6(9):702-713

75. Barnett GC, West CM, Dunning AM, et al. Normal tissue reactions to radiotherapy: towards tailoring treatment dose by genotype. Nat Rev Cancer. 2009;9(2):134-142.

76. Kleibeuker EA, Griffioen AW, Verheul HM, Slotman BJ, Thijssen VL. Combining angiogenesis inhibition and radiotherapy: a double-edged sword. Drug Resist Updat. 2012;15(3):173-182.

77. Imaizumi N, Monnier Y, Hegi M, Mirimanoff RO, Rüegg C. Radiotherapy suppresses angiogenesis in mice through TGF- $\beta$ RI/ALK5dependent inhibition of endothelial cell sprouting. PLoS One. 2010;5(6): e11084.

78. Cheung YT, Ng T, Shwe M, et al. Association of proinflammatory cytokines and chemotherapy-associated cognitive impairment in breast cancer patients: a multi-centered, prospective, cohort study. Ann Oncol. 2015;26(7):1446-1451

79. Klauber N, Parangi S, Flynn E, Hamel E, D'Amato RJ. Inhibition of angiogenesis and breast cancer in mice by the microtubule inhibitors 2-methoxyestradiol and taxol. Cancer Res. 1997;57(1):81-86.

80. Pusztai L, Mendoza TR, Reuben JM, et al. Changes in plasma levels of inflammatory cytokines in response to paclitaxel chemotherapy. Cytokine. 2004;25(3):94-102.

81. Tsavaris N, Kosmas C, Vadiaka M, Kanelopoulos P, Boulamatsis D. Immune changes in patients with advanced breast cancer undergoing chemotherapy with taxanes. Br J Cancer. 2002;87(1):21-27.
82. Rovati B, Mariucci S, Delfanti S, et al. Simultaneous detection of circulating immunological parameters and tumor biomarkers in early stage breast cancer patients during adjuvant chemotherapy. Cell Oncol (Dordr). 2016;39(3):211-228.

83. Mellor RH, Stanton AW, Menadue L, Levick JR, Mortimer PS. Evidence for dermal angiogenesis in breast cancer related lymphedema demonstrated using dual-site fluorescence angiography. Microcirculation. 2002;9(3):207-219.

84. Basbaum AI, Bautista DM, Scherrer G, Julius D. Cellular and molecular mechanisms of pain. Cell. 2009;139(2):267-284.

85. Bunker TD, Reilly J, Baird KS, Hamblen DL. Expression of growth factors, cytokines and matrix metalloproteinases in frozen shoulder. J Bone Joint Surg Br. 2000;82(5):768-773.

86. Karthikeyan S, Griffin DR, Parsons N, et al. Microvascular blood flow in normal and pathologic rotator cuffs. J Shoulder Elbow Surg. 2015;24(12):1954-1960.

87. Levy O, Relwani J, Zaman T, Even T, Venkateswaran B, Copeland S. Measurement of blood flow in the rotator cuff using laser Doppler flowmetry. J Bone Joint Surg Br. 2008;90(7):893-898.

88. Matthews TJ, Hand GC, Rees JL, Athanasou NA, Carr AJ. Pathology of the torn rotator cuff tendon. Reduction in potential for repair as tear size increases. J Bone Joint Surg Br. 2006;88(4):489-495.

89. Bedi A, Maak T, Walsh C, et al. Cytokines in rotator cuff degeneration and repair. J Shoulder Elbow Surg. 2012;21(2):218-227.

90. Lakemeier S, Reichelt JJ, Patzer T, Fuchs-Winkelmann S, Paletta JR, Schofer MD. The association between retraction of the torn rotator cuff and increasing expression of hypoxia inducible factor $1 \alpha$ and vascular endothelial growth factor expression: an immunohistological study. BMC Musculoskelet Disor. 2010;11(1):230.

91. Collado-Hidalgo A, Bower JE, Ganz PA, Irwin MR, Cole SW. Cytokine gene polymorphisms and fatigue in breast cancer survivors: early findings. Brain, Behav Immun. 2008;22(8):1197-1200.

92. Bower JE, Ganz PA, Irwin MR, Castellon S, Arevalo J, Cole SW. Cytokine genetic variations and fatigue among patients with breast cancer. J Clin Oncol. 2013;31(13):1656-1661.

93. Miaskowski C, Elboim C, Paul SM, et al. Polymorphisms in tumor necrosis factor- $\alpha$ are associated with higher anxiety levels in women after breast cancer surgery. Clin Breast Cancer. 2016;16(1):63-71.e3.

94. Gwilym SE, Watkins B, Cooper CD, et al. Genetic influences in the progression of tears of the rotator cuff. $J$ Bone Joint Surg Br. 2009;91(7):915-917.

95. Harvie P, Ostlere SJ, Teh J, et al. Genetic influences in the aetiology of tears of the rotator cuff. Sibling risk of a full-thickness tear. $J$ Bone Joint Surg Br. 2004;86(5):696-700.

96. Motta Gda R, Amaral MV, Rezende E, et al. Evidence of genetic variations associated with rotator cuff disease. J Shoulder Elbow Surg. 2014;23(2):227-235.

97. Maffulli N, Margiotti K, Longo UG, Loppini M, Fazio VM, Denaro $\mathrm{V}$. The genetics of sports injuries and athletic performance. Muscles Ligaments Tendons J. 2013;3(3):173-189.

98. Posthumus M, September AV, O'Cuinneagain D, van der Merwe W, Schwellnus MP, Collins M. The COL5A1 gene is associated with increased risk of anterior cruciate ligament ruptures in female participants. Am J Sports Med. 2009;37(11):2234-2240.

99. Gibbon AP, Hobbs H, van der Merwe W, et al. Polymorphisms of the matrix metalloproteinase-3 gene and the risk of musculoskeletal soft tissue injuries. J Sci Med Sport. 2014;18:e42.

100. Rahim M, Gibbon A, Hobbs H, et al. The association of genes involved in the angiogenesis-associated signaling pathway with risk of anterior cruciate ligament rupture. J Orthop Res. 2014;32(12):1612-1618.

101. Collado-Hidalgo A, Bower JE, Ganz PA, Cole SW, Irwin MR. Inflammatory biomarkers for persistent fatigue in breast cancer survivors. Clin Cancer Res. 2006;12(9):2759-2766.

102. Georgiou GK, Igglezou M, Sainis I, et al. Impact of breast cancer surgery on angiogenesis circulating biomarkers: a prospective longitudinal study. World J Surg Oncol. 2013;11:213. 


\section{Publish your work in this journal}

Cancer Management and Research is an international, peer-reviewed open access journal focusing on cancer research and the optimal use of preventative and integrated treatment interventions to achieve improved outcomes, enhanced survival and quality of life for the cancer patient. The manuscript management system is completely online and includes a very quick and fair peer-review system, which is all easy to use. Visit http://www.dovepress.com/testimonials.php to read real quotes from published authors.

Submit your manuscript here: https://www.dovepress.com/cancer-management-and-research-journal 